\title{
The morphological and molecular susceptibility of sheep and mouse zona pellucida to acrosin
}

\author{
C. R. Brown \\ AFRC Institute of Animal Physiology, Animal Research Station, 307 Huntingdon Road, \\ Cambridge CB3 OJQ, U.K.
}

\begin{abstract}
Summary. The effect of acrosin on the gross morphology and macromolecular constituents of the mouse and sheep zona pellucida has been examined by light microscopy and SDS-PAGE following labelling of the zona with ${ }^{125} \mathrm{I}$. Ram and boar acrosin had similar effects on the sheep zona in that while there was no discernible alteration in the gross morphology of the investment it was proteolysed to the same limited extent by both enzymes; during $1 \mathrm{~h}$ major polypeptides of $M_{\mathrm{r}} 180000$ (present on the zona pellucida of eggs but absent from that of oocytes) and 80000 were hydrolysed, giving rise to polypeptides of $M_{\mathrm{r}} 68000,54000$ and 46000 , of which the last accumulated and represented the lowest molecular weight hydrolysis product. By contrast, the mouse zona pellucida was completely dissolved from the egg by ram acrosin and the investment's macromolecules were extensively hydrolysed.
\end{abstract}

\section{Introduction}

The molecular basis for sperm passage through the zona pellucida, the extracellular glycoprotein matrix which surrounds the mammalian egg, remains obscure. The fact that the sperm acrosome contains several hydrolytic enzymes (McRorie \& Williams, 1974) has led to an acceptance of the concept that these are deployed to digest a pathway through the investment, and of these the proteinase acrosin (EC 3.4.21.10) has been identified as possibly being the major 'zona lysin'. This attribution followed experiments that showed that proteinase inhibitors, not acrosin-specific, could impair fertilization in vivo and in vitro and that preparations of acrosin are able to dissolve the zona pellucida from the egg (see Brown, 1982, for references). In spite of this there has been some doubt about such a role because other functions for the enzyme have been indicated (Green, 1978; Lui \& Meizel, 1979; Saling, 1981) and, in animals of some species, mainly the domesticated species, acrosin has no effect on the gross morphology of the zona pellucida (Brown, 1982; unpublished results). However, more recently it has been demonstrated that, although boar acrosin has no effect on the zona pellucida as judged by light microscopy, the enzyme does effect a limited proteolysis of the investment which is detectable only at the molecular level (Urch, Wardrip \& Hedrick, 1985; Dunbar, Dudkiewicz \& Bundman, 1985; Brown \& Cheng, 1985). These results have provided an interesting contrast to the action of acrosin on the mouse zona pellucida which causes complete dissolution and removal of the investment from the egg (Brown, 1983). Another serine proteinase, chymotrypsin, will also solubilize the mouse zona pellucida and in so doing inflict only a very limited hydrolysis of its component macromolecules (Greve \& Wassarman, 1985). The activity of acrosin on the mouse zona pellucida has not yet been investigated at the molecular level, neither has the action of highly purified homologous acrosin on the zona pellucida of a domesticated species other than the pig. This paper investigates both of these interactions using the sheep as a further domesticated species; in addition the proteolytic effects of homologous and heterologous acrosin on the sheep zona pellucida are compared. 


\section{Materials and Methods}

Chemicals. The reagent $N$-succinimidyl 3-(4-hydroxy, 5-[ $\left.{ }^{125} \mathrm{I}\right]$ iodophenyl) and ${ }^{14} \mathrm{C}$-methylated molecular weight markers were purchased from the Radiochemical Centre, Amersham, Bucks, U.K. Pregnant mare's serum gonadotrophin (PMSG) and human chorionic gonadotrophin (hCG) were purchased from Intervet Laboratories Ltd, Cambridge, U.K., cloprostenol (Estrumate) from Imperial Chemical Industries, Cheshire, U.K. and buserelin (Receptal) from Hoechst U.K. Ltd, Hounslow, Middlesex, U.K. Ovine hyaluronidase (Type V) was obtained from Sigma Chemical Co. Ltd, Poole, Dorset, U.K. All other cnemicals were of the highest grade obtainable.

Medium. A balanced medium pH 7.2 (Trounson, Willadsen \& Rowson, 1976) containing $4 \mathrm{mg}$ bovine serum albumin (BSA)/ml was used for collection of eggs but for acrosin-egg incubations BSA was omitted.

Collection of eggs. Mouse eggs were collected into medium from the oviducts of 26-28-day-old CFLP females previously treated with 12 i.u. PMSG $(66 \mathrm{~h})$ and $12 \mathrm{i} . \mathrm{u}$. hCG $(18 \mathrm{~h})$. The cumulus oophorus and corona radiata were removed with ovine hyaluronidase dissolved at $0.5 \mathrm{mg} / \mathrm{ml}$ in medium after which the eggs were thoroughly washed in medium without BSA and used without delay.

Ovulated sheep eggs were flushed with medium from the oviducts of anaesthetized animals previously injected with $1 \mathrm{ml}$ buserelin $(28 \mathrm{~h}), 0.5 \mathrm{ml}$ cloprostenol $(52 \mathrm{~h})$ and $900 \mathrm{i} . \mathrm{u}$. PMSG (100 h). They were then denuded down to the zona pellucida by gentle pipetting and washed thoroughly in medium without BSA. Sheep oocytes were aspirated from mature follicles of ovaries obtained fresh from a slaughterhouse and prepared for use in the same way.

Preparation of pure acrosins. Ram and boar $\beta$-acrosins were purified using procedures previously described (Brown \& Hartree, 1978; Brown \& Cheng, 1985); briefly these entailed removal from spermatozoa of endogenous acrosin inhibitor followed by acid extraction of spermatozoa and affinity purification of the enzyme using the acrosin inhibitor $p$ - $\left(p^{\prime}-\right.$ aminophenoxypropoxy)-benzamidine linked to Sepharose-4B.

Digestion of sheep zonae pellucidae with ram and boar acrosins. Groups of unlabelled ovulated sheep eggs were incubated at $39^{\circ} \mathrm{C}$ in medium containing ram or boar $\beta$-acrosin at $1 \mathrm{mg} / \mathrm{ml}$. After 3 , 9 and $60 \mathrm{~min}$ they were transferred to $0.02 \mathrm{M}$-p-aminobenzamidine, and washed thoroughly in medium. Each zona pellucida was carefully removed with a Leitz micromanipulator, labelled with ${ }^{125} \mathrm{I}$, and dissolved individually in electrophoresis buffer. Controls consisted of eggs similarly incubated in medium with and without $0.02 \mathrm{M}$ - $p$-aminobenzamidine and of acrosins incubated at $1.0 \mathrm{mg} / \mathrm{ml}$ for the same periods, after which they were made $0.02 \mathrm{M}$ in $p$-aminobenzamidine and ethanol-precipitated for ${ }^{125} \mathrm{I}$-labelling and electrophoresis (see below).

Digestion of mouse zonae pellucidae with ram acrosin. Groups of $\sim 12{ }^{125} \mathrm{I}$-labelled eggs were incubated at $37^{\circ} \mathrm{C}$ in medium containing $1 \mathrm{mg}$ ram $\beta$-acrosin $/ \mathrm{ml}$ until their zonae pellucidae had either thinned to about one third their original thickness or had become completely solubilized. This took about $2 \mathrm{~h}$ and $3.5 \mathrm{~h}$ respectively after which time proteolysis was arrested by addition to the incubation of $0.02 \mathrm{M}$-p-aminobenzamidine. Control eggs received the same treatment without acrosin. The eggs were then sedimented by centrifugation $(500 \mathrm{~g}$ for $5 \mathrm{~min}$ ), the supernatant removed and its protein content precipitated with 9 volumes of cold ethanol. After two washes in $90 \%(\mathrm{v} / \mathrm{v})$ ethanol the precipitate was dissolved in electrophoresis sample buffer. Those eggs with remnant zonae pellucidae were resuspended in medium without bovine serum albumin and the remains of the investment were removed mechanically, combined and dissolved in sample buffer. The gross morphology of zonae pellucidae was assessed microscopically at $\times 80$ magnification.

${ }^{125}$ I-labelling of zonae pellucidae and acrosins. To zonae pellucidae, either in situ (mouse) or detached from the egg (sheep), in $10 \mu \mathrm{l}$ medium was added $2.5 \mu \mathrm{Ci}$ reagent in $20 \mu \mathrm{l} 0.1 \mathrm{M}$-borate 
buffer pH 8.5 (Bolton \& Hunter, 1973). After $15 \mathrm{~min}$ at $25^{\circ} \mathrm{C}$ they were washed well with medium and either used for acrosin digest experiments (mouse) or, having already been exposed to acrosin (sheep), dissolved directly in electrophoresis buffer. Labelling of acrosin controls was carried out using the same concentration of reagent as for zonae pellucidae, after which protein was precipitated with 9 volumes of cold ethanol and dissolved in electrophoresis buffer.

Electrophoresis. Labelled zonae pellucidae and ethanol-precipitated acrosin and acrosin digests were dissolved in sample buffer consisting of $62.5 \mathrm{~mm}-\mathrm{Tris}-\mathrm{HCl} \mathrm{pH} \mathrm{6.8,2 \% (w/v)} \mathrm{SDS} \mathrm{and} 10 \%$ $(\mathrm{w} / \mathrm{v})$ glycerol and analysed on $5-20 \%(\mathrm{w} / \mathrm{v})$ polyacrylamide gradient slab gels $(80 \mathrm{~mm} \times$ $100 \mathrm{~mm} \times 0.5 \mathrm{~mm}$ ) containing $0.1 \%$ SDS. After electrophoresis ${ }^{125}$ I-labelled proteins were detected by autoradiography on Kodak X-Omat S film.

\section{Results}

\section{Differences between the zona pellucida of sheep oocytes and eggs}

Oocytes electrophoresed under reducing conditions separated into two major polypeptides with approximate $M_{\mathrm{r}}$ values of 75000 and 60000 , a minor polypeptide of $M_{\mathrm{r}} \sim 46000$ and a doublet at $M_{\mathrm{r}} 30000$ (Fig. 1A, track a). Under non-reducing conditions (Fig. 1A, track b), the polypeptide of $M_{\mathrm{r}} 60000$ was absent leaving only that of $M_{\mathrm{r}} 75000$ with a spread of labelled material showing a lower molecular weight limit of $M_{\mathrm{s}} \sim 55000$. The polypeptide profile of zonae pellucidae of eggs recovered from the oviduct and electrophoresed under non-reducing conditions was quite different (Fig. 1A, track c); a major polypeptide of $M_{\mathrm{r}} 180000$ was present and the main component of $M_{\mathrm{r}}$ 75000 of the non-reduced oocyte zona consistently migrated with a higher molecular weight of $M_{\mathrm{r}}$ 80000 . Minor bands with $M_{\mathrm{r}}$ values of 49000 and 46000 were also present.

\section{Digestion of sheep zonae pellucidae with ram and boar acrosins}

During the 1-h incubation with acrosin the zona pellucida of ovulated eggs looked unaltered as judged by light microscopy. However, electrophoretic analysis on non-reducing gels showed that they had undergone a limited proteolysis (Fig. 1A, tracks $\mathrm{d}-\mathrm{i}$ ). Incubation for 3 min with boar acrosin resulted in complete removal of the polypeptide of $M_{\mathrm{r}} 80000$ and virtually all of that of $M_{\mathrm{r}}$ 180000 (track g). Instead (tracks $\mathrm{h}$ and i) there were polypeptides with $M_{\mathrm{r}}$ values of 75000,68000 , 54000 and 46000 of which those of $M_{r} 68000$ and 54000 diminished considerably during the course of the incubation while that of $M_{\mathrm{r}} 46000$ accumulated. Ram acrosin had an identical effect except that the rate of proteolysis appeared to be more rapid; thus by 3 min (track d) maximum levels of the polypeptide $M_{\mathrm{r}} 46000$ were present with the concomittant disappearance of the species of $M_{\mathrm{r}} 54000$. Most striking was the limited nature of proteolysis by both enzymes evidenced by the complete absence of material below $M_{\mathrm{r}} 46000$. Since the molecular weight of both acrosins is below $M_{\text {r }} 40000$ (Brown \& Hartree, 1978; Brown \& Cheng, 1985) the enzymes and/or their autolysis products clearly did not bind to the zona pellucida to become labelled and electrophoresed, and acrosin controls confirmed this.

\section{Digestion of mouse zonae pellucidae with ram acrosin}

Ram acrosin will digest and completely remove the zona pellucida from the mouse egg in such a way that the only morphological change discernible is a thinning of the investment which begins at the outer surface and progresses towards the egg (Brown, 1982). It is therefore possible to judge very approximately the proportion of zona pellucida remaining around the egg at a given time during the digestion. Another feature of the dissolution of the mouse zona pellucida by acrosin is 

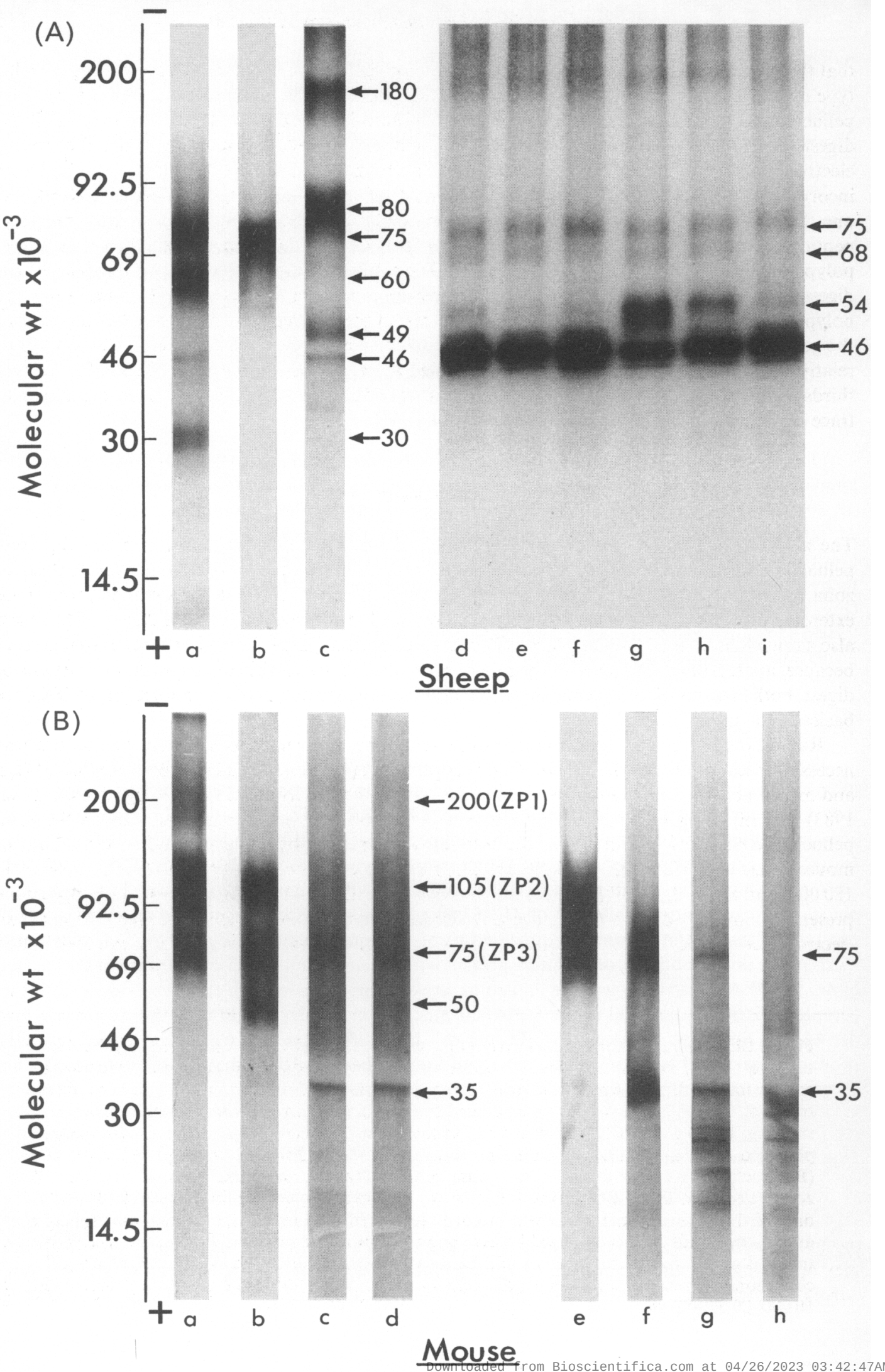
that the process is very uniform from egg to egg, making it possible to combine several eggs for this type of study. Figure 1B illustrates the polypeptide profile of the remaining one third of the zona pellucida still surrounding the egg after digestion by acrosin (tracks $b$ and $f$ ) and also the solubilized digests (tracks c, d, g, h) and these can be compared with untreated zonae (tracks a and e). When electrophoresed under non-reducing conditions, control zonae (track a) showed that label had been incorporated into polypeptides with values for $M_{\mathrm{r}}$ of about 200000,105000 and 75000 . The one-third zona not dissolved by acrosin separated under non-reducing conditions into three polypeptides of $M_{\mathrm{r}} 105000,75000$ and 50000 (track b) and, under reducing conditions, into two polypeptides of $M_{\mathrm{r}} 75000$ and 35000 (track $\mathrm{f}$ ). The soluble fractions from the two thirds and total digests gave an identical pattern under non-reducing conditions (tracks $\mathrm{c}$ and $\mathrm{d}$ ) in that only one polypeptide, $M_{\mathrm{r}} 35000$, was clearly resolved; the rest of the labelled material covered a large area of the gel between $R_{\mathrm{m}}$ values of 105000 and 40000 . When electrophoresed under reducing conditions relatively small amounts of material were resolved at $M_{\mathrm{r}} 75000,35000$ and $<35000$ for the two thirds digestion (track $\mathrm{g}$ ), but after complete removal of the zona pellucida the digest contained no trace of material at $M_{\mathrm{r}} 75000($ track h).

\section{Discussion}

The above results have provided further details about the action of acrosin on the egg zona pellucida and have demonstrated how it may vary between species from a limited proteolysis of zona macromolecules, which leaves the investment in situ and morphologically intact, to a more extensive proteolysis which results in complete removal of the investment from the egg. They have also shown that boar acrosin appears to have the same effect on the sheep zona as does ram acrosin because, apart from a difference in the rate of proteolysis between the two acrosins, the patterns of digest, both in terms of intermediates and the dominant major polypeptide product $\left(M_{\mathrm{r}} 46000\right)$, are basically the same.

Ram acrosin used to digest mouse zonae represents a heterologous system but its use was necessary because of the difficulty in obtaining pure mouse acrosin, and is justified because (i) ram and mouse acrosin will completely remove the zona pellucida from the mouse egg (Brown, 1982, 1983) and (ii) the present results have shown the action of a heterologous acrosin on the zona pellucida to be identical with that of the homologous acrosin. The polypeptides detected in control mouse zonae of $M_{\mathrm{r}} 200000,105000$ and 75000 are the glycoproteins ZP1 $\left(M_{\mathrm{r}} 200000\right), \mathrm{ZP} 2\left(M_{\mathrm{r}}\right.$ $120000)$ and ZP3 $\left(M_{\mathrm{r}} 83000\right)$, respectively, described by Bleil \& Wassarman (1980), although in the present experiments ZP2 and ZP3 have given lower molecular weight values. In preparation for an electronmicroscopical analysis of the structure of the mouse zona, Greve \& Wassarman (1985) used

Fig. 1. SDS-polyacrylamide gel electrophoretograms. (A) Individual sheep zonae pellucidae: tracks a and b, zonae from oocytes electrophoresed under reducing (a) and non-reducing (b) conditions; track $\mathrm{c}$, zona pellucida from an egg electrophoresed under non-reducing conditions; tracks $\mathrm{d}$, e and $\mathrm{f}$, zonae pellucidae incubated for 3,9 and $60 \mathrm{~min}$ respectively with ram acrosin; tracks $g, h$ and $i$, as for tracks $d$, e and $f$ except with boar acrosin. Tracks $d-i$ were electrophoresed under non-reducing conditions. In all cases $\sim 100000$ c.p.m. were applied to the gel. (B) Fractions from the digestion of mouse zonae by ram acrosin: tracks a and e, untreated zonae electrophoresed under non-reducing (a) and reducing (e) conditions; tracks $b$ and $f$, one-third undissolved zona remnant in non-reducing (b) and reducing ( $f$ ) conditions; tracks $c$ and $\mathrm{g}$, two-thirds zona solubilized by acrosin in non-reducing (c) and reducing (g) conditions; tracks $d$ and $h$, zonae completely solubilized by acrosin in non-reducing $(d)$ and reducing $(h)$ conditions. Fractions for each track were obtained from about 12 zonae and contained $10000-20000$ c.p.m. 
chymotrypsin to partly solubilize the investment followed by examination of the insoluble and soluble fractions. Chymotrypsin and acrosin are both serine proteases but with different substrate specificities. After digestion with chymotrypsin the insoluble zona remnant was represented by ZP1, ZP2 and ZP3 when analysed on non-reducing SDS-PAGE. This does not appear to be the case after partial digestion of the mouse zona by acrosin, because the remnant of approximately one third of the original zona contained no ZP1 but polypeptides of $M_{\mathrm{r}} 105000,75000$ and 50000 by non-reducing SDS-PAGE. These appear to be ZP2, ZP3 and an hydrolysis product, although it is possible that products from the hydrolysis of ZP1 could account, at least in part, for any of these. Greve \& Wassarman (1985) found the soluble fraction of mouse zonae digested by chymotrypsin to contain ZP2 as the dominant molecular species but complete absence of ZP1. Acrosin again had a different effect in that under non-reducing conditions ZP2 and ZP3 were not electrophoretically resolvable; the heterogeneity of the digest products caused labelled material to range from $M_{\text {r }}$ 105000 down to $M_{\mathrm{r}} 40000$ except for a well resolved polypeptide of $M_{\mathrm{r}} 35000$. Greve \& Wassarman (1985) did not report an analysis of their fractions on SDS-PAGE under reducing conditions. I found that under such conditions the remnants of undissolved zonae consisted of polypeptides of $M_{\mathrm{r}} 75000$ and 35000 , but no presence of material at the $M_{\mathrm{r}}$ of ZP2. The fractions solubilized by acrosin resolved more clearly when electrophoresed under reducing conditions. Several polypeptides were present in the soluble two-thirds digest including small amounts at the $M_{\mathrm{r}}$ of ZP3 and at $M_{\mathrm{r}} 35000$, but there was no labelling at an $M_{\mathrm{r}}$ greater than 80000 , and indeed after complete removal of the zona the digest contained no trace of ZP3, showing that all constituents had been extensively hydrolysed by the acrosomal enzyme.

It is apparent from analysis on non-reducing SDS-PAGE that the composition of the zona pellucida of sheep eggs recovered from the oviduct is different from that of oocytes recovered from the follicle. In the pig there is a similar difference which is attributable to glycoproteins in the oviduct at oestrus that bind strongly to the zona pellucida immediately after ovulation (Brown \& Cheng, 1986). These glycoproteins of $M_{\mathrm{r}} 250000$ and 90000 behave as substrates for boar acrosin, and the same appears to be the case for the sheep in which the polypeptide of $M_{\mathrm{r}} 180000$ undergoes hydrolysis.

The role of acrosin in fertilization, particularly as a zona lysin, has been much debated (Morton, 1977; Bedford \& Cross, 1978; Brown, 1982; Huneau, Harrison \& Flechon, 1984). Support for the view that the enzyme is not involved in sperm penetration of the zona has stemmed in part from observations that in some species purified acrosins will not alter the gross morphology of the investment (Brown, 1982). However, since it has now been demonstrated that homologous acrosin will alter the molecular composition of the pig (Brown \& Cheng, 1985; Urch et al., 1985; Dunbar et al., 1985) and sheep (present results) zona pellucida and completely remove that of the mouse (Brown, 1983), it seems ever more reasonable to consider that the proteinase is in some way involved in sperm penetration of this investment. The involvement may be in association with other acrosomal hydrolases, which the results for the pig and sheep tend to suggest, although it is possible that limited proteolysis of this relatively porous matrix is sufficient to reduce effectively. its resistance to the thrust generated by the motile spermatozoon (Katz \& deMestre, 1985).

\section{References}

Bedford, J.M. \& Cross, N.L. (1978) Normal penetration of rabbit spermatozoa through trypsin- and acrosinresistant zona pellucida. J. Reprod. Fert. 54, 385-392.

Bleil, J.D. \& Wassarman, P.M. (1980) Structure and function of the zona pellucida: identification and characterization of the proteins of the mouse oocyte's zona pellucida. Devl Biol. 76, 185-203.
Bolton, A.E. \& Hunter, W.M. (1973) The labelling of proteins to high specific activities by conjugation to a ${ }^{125}$ I-containing acylating agent. Biochem. J. 133, 529-539.

Brown, C.R. (1982) Effects of ram sperm acrosin on the investments of sheep, pig, mouse and gerbil eggs. $J$. Reprod. Fert. 64, 457-462. 
Brown, C.R. (1983) Purification of mouse sperm acrosin, its activation from proacrosin and effect on homologous egg investments. J. Reprod. Fert. 69, 289-295.

Brown, C.R. \& Cheng, W.T.K. (1985) Limited proteolysis of the porcine zona pellucida by homologous sperm acrosin. J. Reprod. Fert. 74, 257-260.

Brown, C.R. \& Cheng, W.T.K. (1986) Changes in composition of the porcine zona pellucida during development of the oocyte to the 2- to 4-cell embryo. $J$. Embryol. exp. Morph. 92, 183-191.

Brown, C.R. \& Hartree, E.F. (1978) Studies on ram acrosin. Activation of proacrosin accompanying the isolation of acrosin from spermatozoa and purification of the enzyme by affinity chromatography. Biochem. J. 175;227-238.

Dunbar, B.S., Dudkiewicz, A.B. \& Bundman, D.S. (1985) Proteolysis of specific porcine zona pellucida glycoproteins by boar acrosin. Biol. Reprod. 32, 619-630.

Green, D.P.L. (1978) The activation of proteolysis in the acrosome reaction of guinea-pig sperm. J. Cell Sci. 32, 153-164.

Greve, J.M. \& Wassarman, P.M. (1985) Mouse egg extracellular coat is a matrix of interconnected filaments possessing a structural repeat. J. molec. Biol. 181, 253-264.

Huneau, D., Harrison, R.A.P. \& Flechon, J.E. (1984) Ultrastructural localization of proacrosin and acrosin in ram spermatozoa. Gamete Res. 9, 425-440.
Katz, D.F. \& deMestre, N.J. (1985) Thrust generation by mammalian spermatozoa against the zona pellucida. Biophys. J. 47, 123a, abstr. 154.

Lui, C.W. \& Meizel, S. (1979) Further evidence in support of a role for hamster sperm hydrolytic enzymes in the acrosomal reaction. J. exp. Zool. 297, 173-186.

McRorie, R.A. \& Williams, W.L. (1974) Biochemistry of mammalian fertilization. A. Rev. Biochem. 43, 777-803.

Morton, D.B. (1977) The occurrence and function of proteolytic enzymes in the reproductive tract of mammals. In Proteinases in Cells and Tissues, pp. 445-500. Ed. A. J. Barrett. North Holland, Amsterdam.

Saling, P.M. (1981) Involvement of trypsin-like activity in binding of mouse spermatozoa to zonae pellucidae. Proc. natn. Acad. Sci. U.S.A. 78, 6231-6235.

Trounson, A.O., Willadsen, S.M. \& Rowson, L.E.A. (1976) The influence of in-vitro culture and cooling on the survival and development of cow embryos. $J$. Reprod. Fert. 47, 367-370.

Urch, U.A., Wardrip, N.J. \& Hedrick, J.L. (1985) Limited and specific proteolysis of the zona pellucida by acrosin. J. exp. Zool. 233, 479483 .

Received 11 September 1985 